\title{
BMJ Open Proposal of a clinical care pathway for quality and safe management of headache patients: a consensus study report
}

\author{
Julio Pascual, ${ }^{1,2}$ Patricia Pozo-Rosich (1) ,3,4 Irene Carrillo (1) ,5,6 \\ Sandra Rodríguez-Justo, ${ }^{7}$ Dolores Jiménez-Hernández (i) , 8,9 \\ Almudena Layos-Romero (1) , ${ }^{10}$ Cristina Bailón-Santamaría, ${ }^{1}$ Antonio Torres, ${ }^{11}$ \\ Alba Martínez-García, ${ }^{6}$ Emilio Ignacio, ${ }^{12}$ José Joaquín Mira (D) ${ }^{6,13}$
}

To cite: Pascual J, PozoRosich P, Carrillo I, et al. Proposal of a clinical care pathway for quality and safe management of headache patients: a consensus study report. BMJ Open 2020;10:e037190. doi:10.1136/ bmjopen-2020-037190

- Prepublication history and additional material for this paper are available online. To view these files, please visit the journal online (http://dx.doi. org/10.1136/bmjopen-2020037190).

Received 23 January 2020

Revised 15 July 2020

Accepted 30 September 2020

D Check for updates

(C) Author(s) (or their employer(s)) 2020. Re-use permitted under CC BY-NC. No commercial re-use. See rights and permissions. Published by BMJ.

For numbered affiliations see end of article.

Correspondence to

Irene Carrillo; icarrillo@umh.es

\section{ABSTRACT}

Background Headache is one of the most prevalent and disabling conditions. Its optimal management requires a coordinated and comprehensive response by health systems, but there is still a wide variability that compromises the quality and safety of the care process. Purpose To establish the basis for designing a care pathway for headache patients through identifying key subpathways in the care process and setting out quality and clinical safety standards that contribute to providing comprehensive, adequate and safe healthcare.

Method A qualitative research study based on the consensus conference technique. Eleven professionals from the Spanish National Health System participated, seven of them with clinical experience in headache and four specialists in healthcare management and quality. First, identification of the key subpathways in the care process for headache, barriers/limitations for optimal quality of care, and quality and safety standards applied in each subpathway. Second, two consecutive consensus rounds were carried out to assess the content of the subpathway level descriptors, until the expert agreement was reached. Third, findings were assessed by 17 external healthcare professionals to determine their understanding, adequacy and usefulness.

Results Seven key subpathways were identified:

(1) primary care, (2) emergency department, (3) neurology department, (4) specialised headache unit, (5) hospitalisation, (6) outpatients and (7) governance and management. Sixty-seventh barriers were identified, the most frequent being related to diagnostic errors $(36,1 \%)$, resource deficiency (25\%), treatment errors $(19,4 \%)$, lack of health literacy $(13,9 \%)$ and inadequate communications with care transitions $(5,6 \%)$. Fifty-nine quality and 31 safety standards were defined. They were related to evaluation $(23.3 \%)$, patient safety $(21.1 \%)$, comprehensive care $(12.2 \%)$, treatment $(12.2 \%)$, clinical practice guidelines $(7.8 \%)$, counselling $(6.7 \%)$, training $(4.4 \%)$ and patient satisfaction (3.3\%).

Conclusions This proposal incorporates a set of indicators and standards, which can be used to define a pathway for headache patients and determine the levels of quality.

\section{Strengths and limitations of this study}

- The consensus conference is an appropriate methodology to gather expert knowledge on a specific topic. In this study, 28 experts from different health services in Spain participated in the design of the headache care pathway.

- To our knowledge, this is one of the first studies to provide a detailed description of the headache care pathway with the integration of the different levels of care under a national health system model.

- The headache care pathway has been designed within the framework of the Spanish national health system, limiting its generalisation to other health contexts with different organisational models.

- It was not possible to incorporate the specialty of pharmacy in the development of the study.

\section{INTRODUCTION}

Headache, besides being one of the most prevalent pathologies, generates a high demand for care that makes it one of the most common reasons for consultation in primary care (PC) and neurology. ${ }^{2}$ This condition constitutes one of the most disabling health problems and supposes, for those who suffer from it, a significant socioeconomic impact, secondary to both the direct and indirect costs of the illness, given that, in many cases, it involves absence from work during the most productive years of a person's life. ${ }^{23}$

This impact of this neurological pathology necessitates an effective and coordinated response by healthcare mechanisms. ${ }^{45}$ Thus, diagnostic criteria and treatment guidelines have been established, ${ }^{6}$ response protocols at different levels of care, ${ }^{78}$ care pathways ${ }^{910}$ and the quality of headache treatment has been evaluated. ${ }^{11}$ Despite this, there is high 
variability between countries and health systems in the organisation and design of the care process.

Headache is a pathology that is usually underestimated, which has had a negative impact on the quality of care patients are given, which is sometimes suboptimal. ${ }^{1}$ This poor result is due, in part, to the problems of organisation and coordination between the different levels of care involved in the diagnosis and treatment of these patients. $^{10}$

The quality of care is also affected by the introduction of new classifications and the existence of a multitude of conditioning situations, such as a large number of headache types, the abuse of self-medication, the complexity of the symptoms or the comorbidities associated with this medical condition. ${ }^{2}$

In PC, where most of the patients with headache initially attend, barriers to patient quality and safety have been detected, including underdiagnosis, the omission of referrals when called for by the patient's diagnostic and therapeutic complexity, diagnostic and therapeutic errors and delays in the start of preventive treatments. ${ }^{10}$ There has been an attempt to improve the quality of care of these patients in the emergency department through referral protocols. ${ }^{10}$ On the other hand, errors are also detected in the assessment and diagnosis of headache patients in hospitals that hinder the success of therapeutic interventions. ${ }^{12}$

In this context, the research question that guided this study was how headache patient care can be systematically organised to reduce unnecessary variability and ensure the quality and safety of the care process. Accordingly, the purpose of the study was to establish the basis for designing a care pathway for headache patients through identifying key subpathway in the care process and setting out quality and clinical safety standards that contribute to providing comprehensive, adequate and safe healthcare.

\section{METHODS}

A qualitative research study based on the consensus conference technique among professional experts. This technique consisted in conducting a scientific conference with experts to develop recommendations to address problems related to clinical practice. Among the main advantages of this technique is its adequate performance with heterogeneous groups, which allows very diverse perspectives in multidisciplinary work to be obtained, and its ability to promote consensus among participating experts. ${ }^{1314}$ The study period was between February and September 2019. Figure 1 describes the phases of the study.

First, a study management team was formed made up of representatives of all the specialties involved in the headache patient care process. The management team was responsible for selecting the benchmark clinical practice guidelines, the relevant sources of information, and for defining and validating quality and safety standards, as well as selecting external experts for the final evaluation of the content.

A total of 11 professionals participated in the consensus conference, seven of them with clinical experience in headache patient care (four neurologists, an emergency/PC physician, a health manager and a nurse), and four specialists in healthcare management and quality, including the management of qualitative techniques. This first phase of the study was based on the identification and consensus of the key subpathways in the care process for headache patients and on the graphical representation of possible care flows.

In the first phase, different issues were addressed in a face-to-face session led by a moderator, in which the individual contributions of the participants and other inputs derived from an open debate were compiled. The issues raised in this meeting focused on the subpathways and elements of the care pathway related to quality and clinical safety in the care of headache patients. As a result of this session, the first draft of level descriptors was prepared for each of the subpathways previously identified from the consultation of specialised sources and group work. The structure of the subpathway level descriptors was composed of the following categories of information: (1) description of the subprocess, (2) professionals involved, who intervenes? (3) activities of the subprocess (what activities or interventions are contemplated?), (4) barriers to quality and safety, common pitfalls and errors, (5) standards for adequate and safe care (with the specification of criteria, standards, and sources of information) (table 1). In this session, as well as identifying the subpathways, a first draft of the graphic representation of the possible attention flows was agreed on.

The second phase of the study was carried out through online systems to facilitate debate and consensus-building among experts. In this phase, two consecutive consensus rounds were carried out to assess the content of the subpathway level descriptors and the flow chart, until the agreement was reached between the experts on the management team. Once the consensus rounds were over, the team members made a selection of professionals from their specialty to be invited to participate in the study, contributing their assessment, opinion and experience as members of a panel of experts. This panel was made up of 22 professionals (nine neurologists, three PC physicians, five physicians specialised in family medicine, but assigned to emergency departments, and five health managers from different regions and health services in Spain).

The panel of experts took part in the final phase of external evaluation for the improvement of the subpathway level descriptors prepared, assessing the degree of suitability of the subpathways and their elements, to what extent the barriers identified prevented safe and quality care from being carried out to the headache patient, as well as the degree of suitability of the standards for adequate and safe care. Furthermore, they assessed the contents of these subpathway 


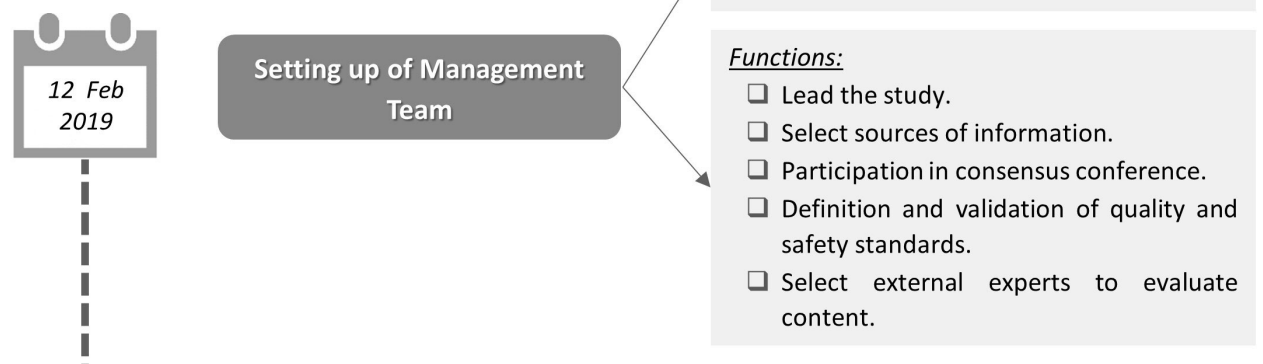

Session task: Identification of milestones and consensual graphic representation of possible care flows.
Lead the study.
$\square$ Select sources of information.
- Participation in consensus conference.
$\square$ Definition and validation of quality and safety standards.
Select external experts to evaluat

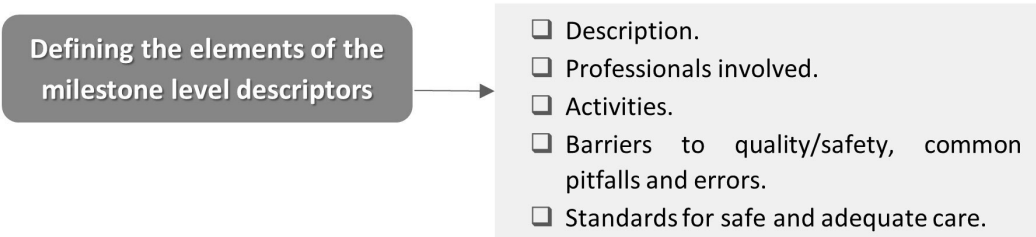

Consensus Conference online (two rounds)
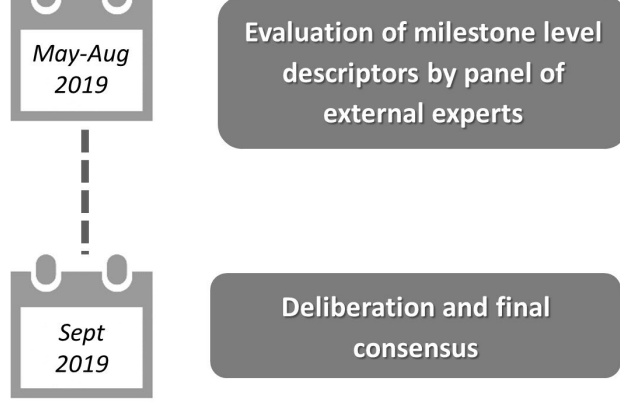

Deliberation and final

consensus

Figure 1 Main phases of the study.

level descriptors in terms of understanding, adequacy and practical usefulness of the information, using a numerical scale from 0 to 10 points. Each panel expert exclusively valued those subpathways related to their professional specialty. Once the evaluation phase was finalised and the contributions made by this panel were incorporated, the final version of the descriptive cards and the flow chart was completed.

Table 1 Definition of descriptive categories of information for each subpathway

\begin{tabular}{|c|c|}
\hline Category of information & Definition \\
\hline Subpathway & $\begin{array}{l}\text { The thread that brings together relevant elements and specific purpose } \\
\text { integrated into the care pathway of the headache patient. }\end{array}$ \\
\hline Description & Features of the corresponding subpathway. \\
\hline Who intervenes & Professionals responsible for the subpathway described. \\
\hline What activities or interventions are contemplated & $\begin{array}{l}\text { Statement of the relevant functions and actions in the course of the } \\
\text { subpathway for the care of the headache patient. }\end{array}$ \\
\hline $\begin{array}{l}\text { Barriers to quality and safety, common pitfalls and } \\
\text { errors }\end{array}$ & $\begin{array}{l}\text { Difficulties and potential quality or safety problems that may hinder the } \\
\text { proper fulfilment of a subpathway. }\end{array}$ \\
\hline
\end{tabular}


Table 2 Professionals and key activities in the different subpathways of the headache patient care process

\begin{tabular}{|c|c|c|c|}
\hline$\#$ & Subpathway & Person(s) involved & Activities \\
\hline 1 & PC & $\begin{array}{l}\text { PC, GP and nursing staff } \\
\text { (follow-up) }\end{array}$ & $\begin{array}{l}\text { Diagnosis (differential and request for tests), therapeutic approach, } \\
\text { health education, monitoring and possible referral to ND or ED. }\end{array}$ \\
\hline 4 & SHU & Neurologist & $\begin{array}{l}\text { Request for additional tests (laboratory and imaging), diagnosis } \\
\text { (history and examination), treatment, follow-up, possible indication } \\
\text { of hospital admission, referral to DH, ND or others and discharge to } \\
\text { PC. }\end{array}$ \\
\hline 6 & Outpatients & $\begin{array}{l}\text { Neurologist and nursing } \\
\text { staff }\end{array}$ & $\begin{array}{l}\text { Diagnostic and therapeutic approach (lumbar puncture, parenteral } \\
\text { treatment). }\end{array}$ \\
\hline 7 & $\begin{array}{l}\text { Governance and } \\
\text { management }\end{array}$ & $\begin{array}{l}\text { Administrators, senior and } \\
\text { middle management }\end{array}$ & $\begin{array}{l}\text { Guarantee the availability of the necessary means for adequate } \\
\text { care, the appropriate professional competencies of the personnel } \\
\text { involved, and the ongoing evaluation of the structure, processes and } \\
\text { outcomes to ensure comprehensive, coordinated and accessible } \\
\text { healthcare for the headache patient. }\end{array}$ \\
\hline
\end{tabular}

DH, day hospital; ED, emergency department; EP, emergency physician; GP, general practitioner; HIT-6, six-item headache impact text; MIDAS, migraine disability assessment scale; ND, neurology department; PC, primary care; SHU, specialised headache unit.

\section{Patient and public involvement}

Patients or the public were not involved in any phase of this study.

\section{RESULTS}

\section{Key subpathways in the care pathway for headache patients}

Seven key subpathways were identified in the process of comprehensive headache patient care: (1) PC, (2) emergency department, (3) neurology department, (4) specialised headache unit, (5) hospitalisation, (6) outpatients and (7) governance and management (table 2). The integration of these seven subpathways in the care pathway is represented in the flow chart shown in figure 2. This diagram does not represent the path that all headache patients necessarily follow, but tries to capture all the possibilities and casuistry of care. Therefore, the full descriptive cards for each subpathway are available in the online supplemental material. Subpathway 3, which is referred to as the department of neurology (general consultation), was subdivided into two descriptive cards, one corresponding to the diagnostic process (3A) and the other to the treatment process (3B), for greater clarity of information.

\section{Barriers to quality and clinical safety}

For the first six subpathways identified in the headache patient care process, a total of 67 barriers/limitations were identified that, according to experts, prevented or hindered the provision of safe and quality care (table 3). The subpathway in which the greatest number of barriers were concentrated was number 3, corresponding to the general consultation of the department of neurology (20.9\% related to diagnosis-3A and $19.4 \%$ to treatment-3B).

The barriers present in a greater number of subpathways of the headache patient care process were classified into five categories: diagnostic errors $(36.1 \%)$, resource deficiency $(25 \%)$, treatment errors $(19.4 \%)$, lack of health literacy $(13.9 \%)$, and inadequate communications with care transitions $(5.6 \%)$ (table 4$)$.

\section{Criteria and standards for adequate and safe care}

A total of 59 quality and 31 safety criteria and standards were defined. The standards were related to evaluation (21, 23.3\%), patient safety $(19,21.1 \%)$, comprehensive care $(11,12.2 \%)$, treatment $(11,12.2 \%)$, compliance with clinical practice guidelines $(7,7.8 \%)$, counselling $(6$, $6.7 \%)$, training $(4,4.4 \%)$, patient satisfaction $(3,3.3 \%)$ and others $(8,8.9 \%)$. 


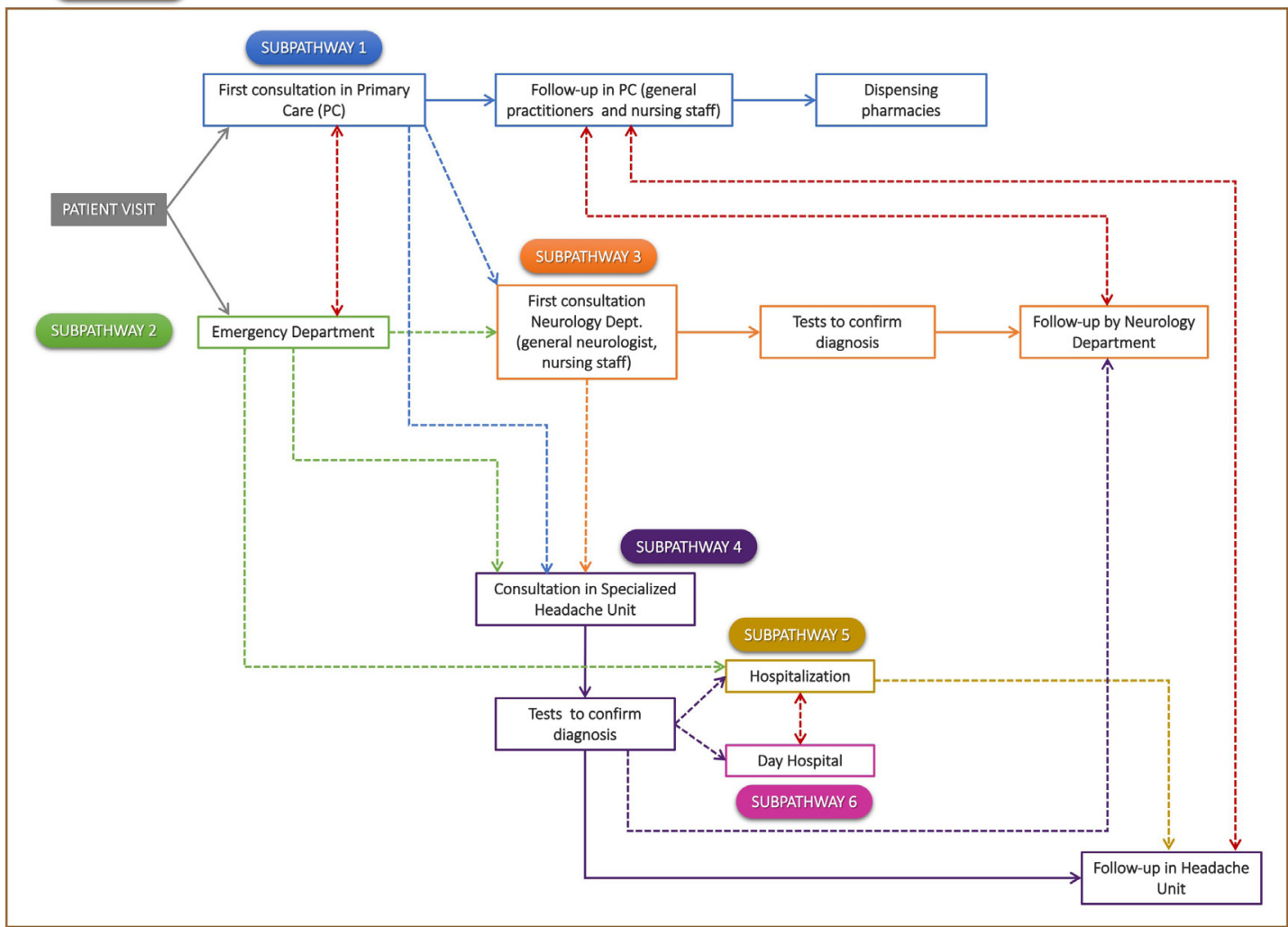

Figure 2 Descriptive flow chart of the care pathway for the headache patient

figure 2Note: Dotted arrows indicate referral paths to other levels of care. The red bidirectional arrows indicate that the referral path can be used in both directions.

\section{Evaluation of content by the panel of external experts}

Seventeen professionals not belonging to the project team participated in the external evaluation process of the subpathway level descriptors and contents developed by the team itself (response rate of $77.3 \%$ ). Table 5 shows the results of this evaluation.

Generally speaking, experts positively evaluated the contents of the subpathway level descriptors drawn up with

Table 3 Barriers to quality and safety and common pitfalls and errors in six of the seven subpathways of the headache patient care process

\section{No of barriers identified in} each subpathway

\section{Subpathway 1. Primary care. Identification, therapeutic approach and possible referral}

11

Subpathway 2. Emergency department. Triage, assessment, treatment and referral to primary 9 care or neurology department (general or specialised headache unit) or admission in hospital

\section{Subpathway 3. Neurology Department (general consultations).

A. Diagnostic and therapeutic approach of the headache patient in general neurology consultations

B. Identification, therapeutic approach and possible referral in the neurology department, general neurologist to headache neurologist

Subpathway 4. Consultation in specialised headache unit. Request for complimentary tests, diagnosis, treatment, follow-up and possible hospital admission or referral to day hospital, neurology department or primary care

Subpathway 5. Hospitalisation. Identification, therapeutic approach during hospitalisation Subpathway 6. Therapeutic approach in day hospital/outpatients 8

A and B represent closely related elements of subpathway 3 (general consultation in the neurology department). The separation of these elements has been done with the only purpose of differentiating the barriers that hinder the correct diagnosis of headache (A) from those that affect the adequate therapeutic approach (B). 
Table 4 Most relevant barriers to achieving optimal care quality

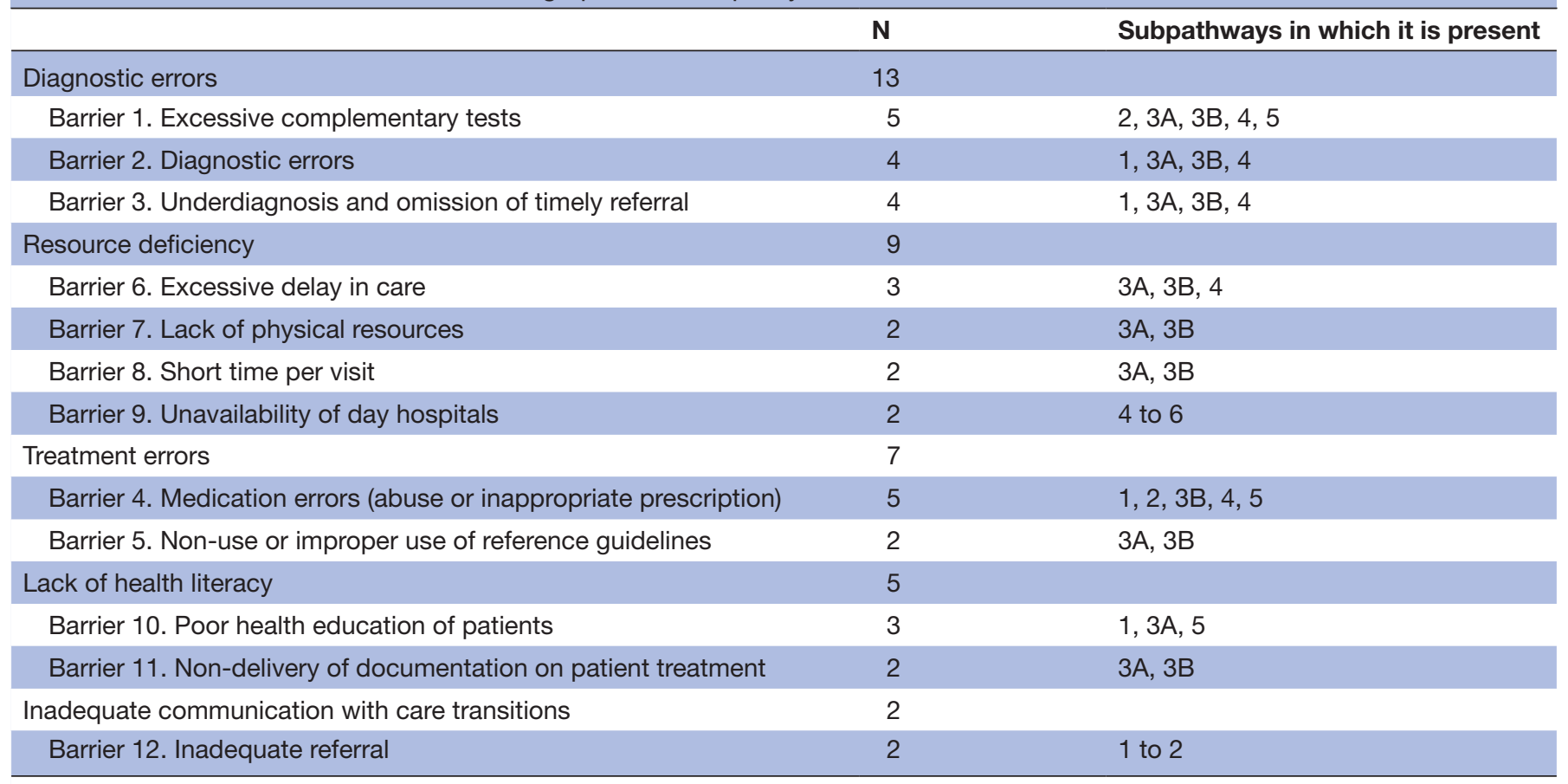

$\mathrm{N}$, number of times experts pointed out this barrier as limiting the quality of care.

an average value of at least eight points in each of the evaluation categories (understanding, adequacy and usefulness). The best-rated subpathways were in this order: management, consultation in specialised headache units and emergencies. Likewise, those considered most useful for their practical application were those related to management, emergency and PC. According to neurologists, the main focus was to improve the practical usefulness of the content related to the treatment process in general neurology (subpathway 3.2) whose score did not reach 7 points.

\section{DISCUSSION}

Analysing the pathway followed by the headache patient in the course of the healthcare they receive, considering all the options and the differences in the complexity of their clinical situation, makes it possible to address the evaluation and improvement of healthcare quality and patient safety. This study is framed within this line of work initiated by the Global Campaign against Headache ${ }^{5}$ conducted by lifting the burden (LTB) in direct contact with WHO.

Table 5 External evaluation of the level descriptors for each subpathway identified in the headache patient care process

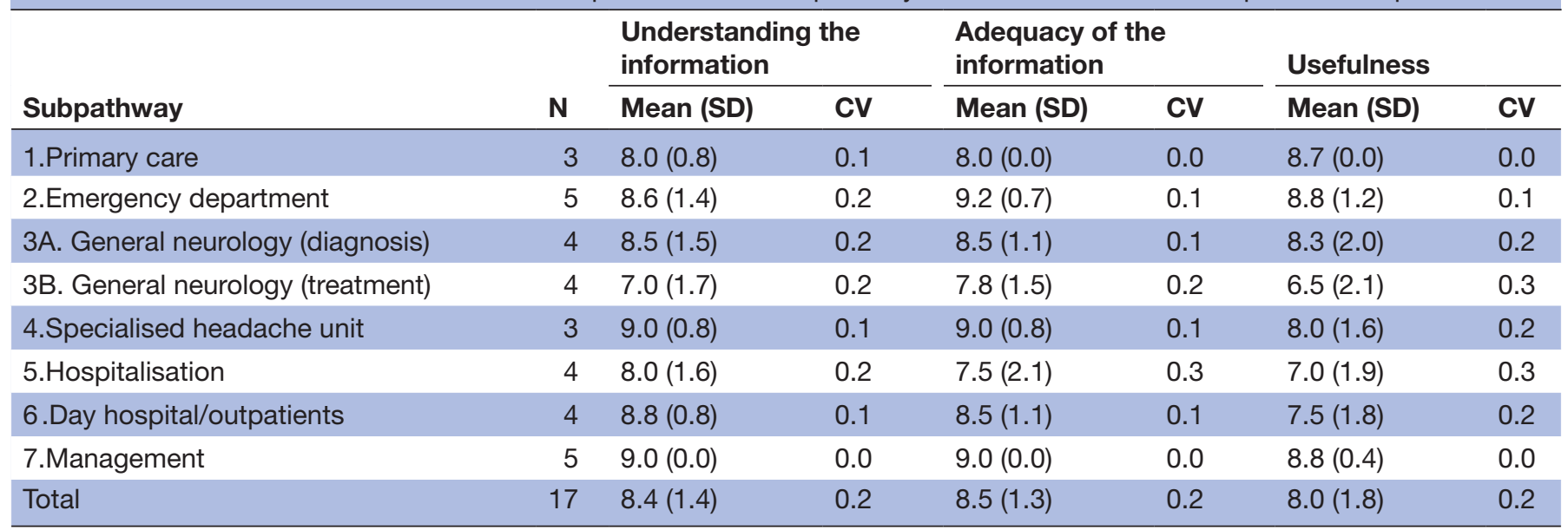

CV, coefficient of variation. 
In the framework of this worldwide project, LTB in collaboration with the European Headache Federation promoted the creation of a service quality evaluation (SQE) group of health services researchers and headache specialists. This team of professionals developed a set of 30 indicators organised in nine domains to assess the quality of headache services ${ }^{15}$ that has been validated in 12 European countries ${ }^{16-18}$ Recently, Steiner et al ${ }^{19}$ have continued this initiative by defining the 10 roles that headache centres play within broader and more structured services and 10 performance standards. These studies already provide a set of validated indicators to detect and rectify deficiencies in the care of headache patients, focusing on the level of specialised care.

This study aimed to integrate the different pathways and levels of care that coexist in the management of headache patients following the work initiated by other authors. ${ }^{5}{ }^{15-19}$ The analysis of barriers and quality standards was carried out considering the whole pathway, followed by the patients.

Health professionals, from different specialties, who participated in this study agreed to identify seven key subpathways in the care process of headache patients: PC consultations, emergency department, neurology department consultations, specialised headache unit consultations, hospitalisation and day hospitals/outpatients, to which a final category related to administration and management has been added. These subpathways are in line with the organisational proposals of care for headache patients. ${ }^{7}$ The experience of the experts and the enormous coincidence with the rest of the health professionals involved in this study, coming from the different levels of care and management involved in providing care in the 'headache' process, have allowed us to establish a broad consensus on these findings.

The comparative analysis between the indicators defined in the Global Campaign against Headache ${ }^{15}$ and those in our proposal indicates a high level of agreement, although each model has its particularities. First, the international proposal offers a global and broad vision of the determinants involved in the quality of specialised headache care, while our study structures the set of indicators according to the subpathways of the care process. Second, our proposal delves into the domains C (appropriate referral pathways) and I (safety of care) proposed by Peters $e t a l^{15}$ and does not contemplate others such as that referred to the convenience and comfort of the centre. Third, our study provides more specific indicators regarding treatments (opioids, triptans, oxygen therapy, etc) and patient profiles. Finally, we also include other aspects not covered by the SQE such as telemedicine, overuse or inadequate use of diagnostic tests, and governance and management indicators. In summary, both proposals present elements in common and differ in others that enrich each of the approaches making them complementary.

In this study, we not only identify the main subpathways of the headache process, but we study their potential barriers and define those criteria and standards necessary to achieve adequate and safe care. For the six healthcare subpathways, the panel of experts and reviewers identified a total of 67 barriers that in their opinion prevent, or at least hinder, safe and quality care. The barriers identified as most frequent were concentrated in the Neurology Department's subpathway and were related to diagnostic errors and resource deficiency. This suggests that the implementation of the recommendations of the guidelines for headache treatment should be reinforced. ${ }^{6}$ It is striking that these results indicate that a high number of medication errors (abuse or inappropriate prescription), an excess of complementary tests, and diagnostic errors continue to occur. Other studies support this data. For example, in Spain less than 20\% of migraine patients receive the prescription of a triptan (of choice in the symptomatic treatment of moderate-intense crises), ergotics and opioids are still prescribed to a significant number of patients although we know that they induce headache chronicity and there is an underuse of preventive treatment. ${ }^{20}$ As for diagnostic barriers, and probably due to an excessively sharp interpretation of the diagnostic criteria of the different primary headaches, the classification of the different headaches remains a problem for primary headaches, which is undoubtedly one of the causes that justify the excess of diagnostic tests, also identified as a barrier. ${ }^{21} 22$ The results of this study, which identify the main barriers in the care pathway for headache patients, could help to introduce the necessary organisational modifications to achieve optimal quality of care following the standards that the European scientific literature has indicated as appropriate. ${ }^{5}$ 15-19 The implementation of these organisational measures could be facilitated by conducting a shared reflection involving all stakeholders in the headache care pathway, including patient representatives.

There are several reasons to try, as we propose in this work, to establish a care pathway for the headache patient process. Headache is, by far, the main cause of neurological consultation by frequency, at different levels of care (PC, neurology and emergency department). ${ }^{23-25}$ The demonstration of the efficacy of botulinum toxin type A in patients with pathology as frequent and disabling as chronic migraine undoubtedly makes a better organisation of headache consultations in neurology departments necessary. ${ }^{26}{ }^{27}$ Finally, the advent of new therapeutic options, such as calcitonin gene-related peptide antagonists ${ }^{28}$ or various neuromodulation devices, ${ }^{29}$ which cost more than the current options, will force us to further optimise care for headache patients, especially at the level of hospital neurology departments.

This work also defined a large panel of 59 quality and 31 safety indicators in the process of headache patients. At a time like the present, in which the efficiency and sustainability of the healthcare system must prevail in the management of healthcare processes, and therefore, the health outcomes for patients, we believe that these results can serve as a basis when it comes to planning and 
evaluating the 'headache' process at different levels of care, something that seems necessary in the immediate future.

\section{Limitations}

This study was developed within the framework of the Spanish health system, so experiences in headache care may differ in other countries. The health structure and the organisational model of PC condition the identification of subpathways and barriers so that their generalisation to other health models should be carried out with caution. For example, not all countries have specialised headache units, and the role that nursing plays in health education and the mobilisation of patients to cope with the illness is quite different. It is possible that the proposal presented can be easily adapted in countries with a national health system as in Spain, while it cannot be extrapolated to countries with another care model. Furthermore, the non-participation of patients in the design of the pathway is also a significant limitation of the study. The care pathway described, developed under the premise of an integrated approach, should incorporate the patient's perspective to ensure person-centred care. In this study, we tried to minimise this bias by involving professionals with extensive experience in the management and care of patients who could provide information on the experience and perspective of patients.

\section{Conclusions}

The design of the headache care pathway that is proposed as a result of this study advises establishing seven key moments or subpathways in healthcare provision. This design should consider the barriers that currently occur and prevent optimal quality and anticipate their limitations in providing high-quality care to this patient profile. In this regard, the experts who have participated in the group work came to agree that, although there are reference guidelines, they are not always used in a practical sense for very different reasons, ranging from budgetary to organisational issues. Finally, this proposal incorporates a set of quality indicators for each of the subpathways, with their recommended standards, which would allow professionals to know the levels of quality at different stages of care for headache patients.

\section{Author affiliations}

${ }^{1}$ Service of Neurology, University Hospital Marqués de Valdecilla and Valdecilla Biomedical Research Institute, Santander, Cantabria, Spain

${ }^{2}$ Department of Medicine, University of Cantabria, Santander, Cantabria, Spain ${ }^{3}$ Headache Unit, Neurology Department, Vall d'Hebron University Hospital, Barcelona, Catalonia, Spain

${ }^{4}$ Headache Research Group, Vall d'Hebron Research Institute (VHIR), Universitat Autònoma de Barcelona, Barcelona, Catalonia, Spain

${ }^{5}$ Foundation for the Promotion of Health and Biomedical Research of Valencia Region (FISABI0), Sant Joan d'Alacant, Valencia Region, Spain

${ }^{6}$ Department of Health Psychology, Miguel Hernández University, Elche, Valencia Region, Spain

${ }^{7}$ Emergency Department, Complejo Hospitalario de Vigo, Vigo, Galicia, Spain ${ }^{8}$ Neurology Department, Virgen del Rocío University Hospital, Seville, Andalusia, Spain

${ }^{9}$ Faculty of Medicine, University of Seville, Seville, Andalusia, Spain
${ }^{10}$ Headache Unit, Neurology Department, University Hospital of Albacete, Albacete, Castile-La Mancha, Spain

${ }^{11}$ Andalusian Agency for Healthcare Quality, Seville, Andalusia, Spain

${ }^{12}$ Department of Nursing and Physiotherapy, University of Cadiz, Cadiz, Andalusia, Spain

${ }^{13}$ Alicante-Sant Joan Health District, Alicante, Valencia Region, Spain

Acknowledgements The authors thank the involvement in the study of the PROMETE0173 Research Group (Generalitat Valenciana, 2017).

Contributors JJM and El conceived and designed the work. AM-G and IC provided methodological support in the conduct of the qualitative techniques. JP, PP-R, SR-J, DJ-H, AL-R, CB-S and AT were responsible for providing the information for the elaboration of the headache pathway and recruiting external professionals for the evaluation of the subpathways' cards. El, JJM, IC and AM-G analysed and interpreted the data. IC and AM-G wrote a draft of the manuscript, which was critically reviewed for important intellectual content by JJM. All authors reviewed the draft and approved the final version of the manuscript. El and JJM took responsibility for the integrity of the work as a whole, from inception to the finished article.

Funding This study was carried out with non-restrictive funding from Novartis (grant number: 1809060787).

Disclaimer The need for ethics approval for this research does not apply according to Spanish regulations.

Competing interests This study has been sponsored by Novartis, but no laboratory professional has been involved in the design of the work, recruitment of professionals, data collection and analysis, or in the interpretation of the results. The authors of the paper have developed the entire process of execution of the study independently.

Patient consent for publication Not required.

Provenance and peer review Not commissioned; externally peer reviewed.

Data availability statement All data relevant to the study are included in the article or uploaded as online supplemental information. Data are available on reasonable request.

Supplemental material This content has been supplied by the author(s). It has not been vetted by BMJ Publishing Group Limited (BMJ) and may not have been peer-reviewed. Any opinions or recommendations discussed are solely those of the author(s) and are not endorsed by BMJ. BMJ disclaims all liability and responsibility arising from any reliance placed on the content. Where the content includes any translated material, BMJ does not warrant the accuracy and reliability of the translations (including but not limited to local regulations, clinical guidelines, terminology, drug names and drug dosages), and is not responsible for any error and/or omissions arising from translation and adaptation or otherwise.

Open access This is an open access article distributed in accordance with the Creative Commons Attribution Non Commercial (CC BY-NC 4.0) license, which permits others to distribute, remix, adapt, build upon this work non-commercially, and license their derivative works on different terms, provided the original work is properly cited, appropriate credit is given, any changes made indicated, and the use is non-commercial. See: http://creativecommons.org/licenses/by-nc/4.0/.

\section{ORCID iDs}

Patricia Pozo-Rosich http://orcid.org/0000-0003-0796-4702

Irene Carrillo http://orcid.org/0000-0002-6981-7284

Dolores Jiménez-Hernández http://orcid.org/0000-0001-9424-6973

Almudena Layos-Romero http://orcid.org/0000-0002-6828-7808

José Joaquín Mira http://orcid.org/0000-0001-6497-083X

\section{REFERENCES}

1 López-Bravo A, Bellosta-Diago E, Viloria-Alebesque A, et al. Headache as a reason for consultation: the primary care perspective. Neurologia 2018;S0213-4853(18)30183-X. doi:10.1016/j. nrl.2018.06.003. [Epub ahead of print: 30 Jul 2018].

2 Pérez Pereda S, Toriello Suárez M, González Quintanilla V, et al. Necesidad real Y consumo de recursos en Las unidades de cefalea: Estudio observacional retrospectivo sobre Una cohorte en Cantabria. Rev Neurol 2019;68:510-6.

3 Vo P, Fang J, Bilitou A, et al. Patients' perspective on the burden of migraine in Europe: a cross-sectional analysis of survey data in 
France, Germany, Italy, Spain, and the United Kingdom. $J$ Headache Pain 2018;19:82.

4 Stovner LJ, Andrée C. Prevalence of headache in Europe: a review for the Eurolight project. J Headache Pain 2010;11:289-99.

5 Steiner TJ, Alliance WH, World Headache Alliance. Lifting the burden: the global campaign against headache. Lancet Neurol 2004;3:204-5.

6 Ezpeleta D, Pozo P. Guía oficial de práctica clínica en cefaleas de la Sociedad Española de Neurología. Madrid: Luzán, 2015: 5.

7 Steiner TJ, Antonaci F, Jensen R, et al. Recommendations for headache service organisation and delivery in Europe. $J$ Headache Pain 2011;12:419-26.

8 Laughey WF, Holmes WF, MacGregor AE, et al. Headache consultation and referral patterns in one UK general practice. Cephalalgia 1999;19:328-9.

9 Peters M, Perera S, Loder E, et al. Quality in the provision of headache care. 1: systematic review of the literature and commentary. J Headache Pain 2012;13:437-47.

10 Gago-Veiga AB, García-Azorín D, Mas-Sala N, et al. How and when to refer patients diagnosed with primary headache and craniofacial neuralgia in the emergency department or primary care: recommendations of the Spanish Society of Neurology's headache Study Group. Neurologia 2020;35:176-84.

11 Pozo-Rosich P, Martínez-García A, Pascual J, et al. Quality assurance in specialized headache units in Spain: an observational prospective study. J Headache Pain 2019;20:73.

12 Santos-Lasaosa S, Vinueza-Buitrón PR, Velázquez-Benito A, et al. Estudio de concordancia diagnóstica en cefalea entre neurología $Y$ atención primaria. Rev Neurol 2016;62:549-54.

13 Halcomb E, Davidson P, Hardaker L. Using the consensus development conference method in healthcare research. Nurse Res 2008;16:56-71.

14 Jones J, Hunter D. Consensus methods for medical and health services research. BMJ 1995;311:376-80.

15 Peters M, Jenkinson C, Perera S, et al. Quality in the provision of headache care. 2: defining quality and its indicators. J Headache Pain 2012;13:449-57.

16 Katsarava Z, Gouveia RG, Jensen R, et al. Evaluation of headache service quality indicators: pilot implementation in two specialist-care centres. J Headache Pain 2015;16:537.
17 Schramm S, Uluduz D, Gouveia RG, et al. Headache service quality: evaluation of quality indicators in 14 specialist-care centres. $J$ Headache Pain 2016;17:111.

18 Pellesi L, Benemei S, Favoni V, et al. Quality indicators in headache care: an implementation study in six Italian specialist-care centres. $J$ Headache Pain 2017;18:55.

19 Steiner TJ, Göbel H, Jensen R, et al. Headache service quality: the role of specialized headache centres within structured headache services, and suggested standards and criteria as centres of excellence. J Headache Pain 2019;20:24.

20 Mateos Marcos V, Porta Etessam J, Armengol Bertolín S, et al. Situación de partida $Y$ abordaje asistencial de la migraña en Las consultas de neurología de España. Estudio PRIMERA. Rev Neurol 2012;55:577-84.

21 Pascual J, Río Sdel, Jiménez JM, et al. Actitud del neurólogo español frente a la migraña: resultados del proyecto CIEN-MIG (I). Rev Neurol 2010;50:577-83.

22 Pascual J, Sánchez-Escudero A, Castillo J. Necesidades de formación del médico de atención primaria en cefaleas. Neurología 2010;25:104-7.

23 Martín Santidrian MA, Jiménez M, Trejo Gabriel JM, et al. A descriptive analysis of ambulatory neurological care demand in Burgos health area. Neurologia 2011;26:39-44

24 Figuerola A, Vivancos J, Monforte C, et al. Registro de las urgencias neurológicas en un Hospital terciario. Rev Neurol 1998;27:750-4.

25 Ruiz M, León C, Castillo J, et al. Distribución POR diagnósticos de las cefaleas que acuden a Los servicios de urgencias de atención primaria. SEMERGEN - Medicina de Familia 2010;36:10-15.

26 Bruloy E, Sinna R, Grolleau J-L, et al. Botulinum toxin versus placebo: a meta-analysis of prophylactic treatment for migraine. Plast Reconstr Surg 2019;143:239-50.

27 Herd CP, Tomlinson CL, Rick C, et al. Botulinum toxins for the prevention of migraine in adults. Cochrane Database Syst Rev 2018;6:CD011616.

28 Charles A, Pozo-Rosich P. Targeting calcitonin gene-related peptide: a new era in migraine therapy. Lancet 2019;394:1765-74.

29 Belvís R, Irimia P, Seijo-Fernández F, et al. Neuromodulación en cefaleas Y neuralgias craneofaciales: Guía de la Sociedad Española de Neurología Y de la Sociedad Española de Neurocirugía. Neurología 2020 